\title{
Pulmonary Congestion Due to Right and Left Heart Output Mismatching: A Case Report and Literature Review
}

\author{
Jing Yuan ${ }^{1}$, Yongjun $L i^{2}$ and Jie Sun ${ }^{1 *}$ \\ ${ }^{1}$ Department of Anesthesiology, Zhongda Hospital, Southeast University, Nanjing, China, ${ }^{2}$ Department of Anesthesiology, \\ Lianshui County People's Hospital, Huai'an, China
}

We report a new pulmonary circulation model during cardiopulmonary bypass that is able to cause pulmonary congestion but without left heart failure. This kind of congestion is characterized by right and left heart output mismatching. The pathophysiological mechanism, clinical manifestations, diagnosis, differential diagnosis, and treatment of this pulmonary congestion are reviewed and discussed in the following article.

Keywords: pulmonary congestion, cardiopulmonary bypass, left atrial pressure, bronchospasm, anesthesia

\section{OPEN ACCESS}

Edited by:

Bruno Moreira Silva,

Federal University of São Paulo, Brazil

Reviewed by:

Attila Kiss,

Medical University of Vienna, Austria Bryan Joseph Taylor,

Mayo Clinic Florida, United States

${ }^{*}$ Correspondence:

Jie Sun

dgsunjie@hotmail.com

Specialty section:

This article was submitted to Clinical and Translational Physiology, a section of the journa Frontiers in Physiology

Received: 08 February 2021 Accepted: 19 March 2021 Published: 13 April 2021

Citation:

Yuan J, Li Y and Sun J (2021) Pulmonary Congestion Due to Right and Left Heart Output Mismatching:

A Case Report and Literature Review. Front. Physiol. 12:665483. doi: 10.3389/fphys.2021.665483

\section{CASE}

A 74-year-old female patient who had mitral valve regurgitation (MR) was admitted to our hospital because of progressive dyspnea for 6 years, and her illness worsened during the previous 2 months. Her body weight and height were $56 \mathrm{~kg}$ and $152 \mathrm{~cm}$, respectively. She had been diagnosed with MR for 2 years and had received diuretic and inotropic therapy for a couple of months. After a preoperative physical examination, a systolic murmur (grade 4/6) was identified by cardiac auscultation at the heart apex, and the boundary of heart dullness was found to expand to the left. Transthoracic echocardiography (TTE) revealed a posterior mitral valve leaf prolapse with severe MR. In addition, the patient still had mild-to-moderate tricuspid valve regurgitation, and the pressure gradient was estimated to be $67 \mathrm{mmHg}$ according to the Bernoulli equation. The left ventricular diameter was $52 \mathrm{~mm}$ at the section of papillary muscles, and the ejection fraction (EF) value was $74.5 \%$. An electrocardiogram (ECG) showed sinus rhythm with a heart rate (HR) of 73 beats per minute (bpm). A chest computed tomography (CT) scan did not reveal any obvious abnormalities except for a sign of heart shadow enlargement. The patient denied any previous disease history and did not take any medication before this illness. Preoperative anesthetic assessments indicated that she was classified as American Society of Anesthesiologists III status (ASA III) and the surgical risk score was 6 (EuroSCORE of 6). The surgeons decided to replace her mitral valve under cardiopulmonary bypass (CPB).

Before anesthesia induction, the invasive blood pressure (IBP) was $138 / 62 \mathrm{mmHg}$ after left radial artery A-line establishment. The ECG demonstrated sinus rhythm and the HR was $62 \mathrm{bpm}$. The pulse oxygen saturation $\left(\mathrm{SpO}_{2}\right)$ value was $94 \%$ at room air. After induction of anesthesia with $4 \mathrm{mg}$ midazolam, $50 \mathrm{mg}$ propofol, $0.5 \mathrm{mg}$ fentanyl, and $16 \mathrm{mg}$ vecuronium bromide, the patient underwent tracheal intubation with an ID $7.0 \mathrm{~mm}$ tube and was then connected to an anesthetic machine for ventilation. At first, the tidal volume was $450 \mathrm{ml}$ and the respiratory rate was $10 \mathrm{bpm}$. The inspiratory to expiratory ratio was set at 1:2 without an inspiratory pause. The peak airway pressure was $20 \mathrm{cmH}_{2} \mathrm{O}$ with the presence of a positive end-expiratory pressure (PEEP) of $5 \mathrm{cmH}_{2} \mathrm{O}$. End-tidal carbon dioxide $\left(\mathrm{ETCO}_{2}\right)$ was maintained between 35 and $45 \mathrm{mmHg}$ by 
subsequently adjusting the ventilation frequency. The patient's hemodynamics, $\mathrm{SpO}_{2}$, and $\mathrm{ETCO}_{2}$ were stable and were maintained in the normal range during anesthesia induction. After placement of a transesophageal echocardiography (TEE) probe and a Swan-Ganz catheter, the central venous pressure (CVP), pulmonary artery pressure (PAP), and cardiac output were monitored. The baseline PAP was $56 / 22 \mathrm{mmHg}$ after Swan-Ganz catheter placement. Anesthesia was maintained with sevoflurane, cis-atracurium, intermittent fentanyl, and the bispectral index (BIS) value was maintained at 40-60 during most time of the surgical procedure.

After about $60 \mathrm{~min}$ of mitral valve replacement, the heart began to re-beat successfully after releasing the aortic clamp. The heart contractility seemed good with the help of dobutamine administered at a rate of $5 \mu \mathrm{g} / \mathrm{kg} / \mathrm{min}$. The anesthesiologist found that the peak airway pressure increased gradually from 20 to $38 \mathrm{cmH}_{2} \mathrm{O}$ after resuming ventilation under the previous ventilator settings. The PAP was not high $(10 \mathrm{mmHg})$ because the patient was still dependent on the CPB machine. The anesthesiologist excluded an inadequate anesthesia depth, airway circuit obstruction, anesthetic machine problems, pleural cavity, or mediastinal abnormalities for a short period of time. Fibrotic bronchoscopy did not reveal bronchus intubation or any obvious secretions. Bronchospasm was initially diagnosed and bronchial dilators together with sevoflurane were administered, but without any obvious effect to relieve the airway pressure. Because bronchospasm usually happens in light anesthetic state and what is more, volatile anesthetics can dilate bronchus directly. Even if it was difficult to listen to breath sound because of aseptic towel, we tried to obtain the breath sound in the two lungs. As pulmonary auscultation did not indicate obvious wet or dry rales and $\mathrm{ETCO}_{2}$ waveform did not indicate small airway obstruction, the anesthesiologist began to consider cardiogenic factors. At that time, the IBP was 75/65 $\mathrm{mmHg}$ and HR was $90 \mathrm{bpm}$.

Transesophageal echocardiography examination did not reveal any obvious myocardial contraction abnormalities and the $\mathrm{CPB}$ machine perfusion rate was $3.2 \mathrm{~L} / \mathrm{min}$. The blood reservoir showed significantly decreased venous return during this period but the surgeons did not note any obvious bleeding around the surgical field. The Swan-Ganz catheter indicated that the right heart stroke volume was much more than the sum of left ventricular outflow tract (LVOT) blood flow volume and the left atrial suction rate. Through echo measurements and calculation, we can get the left ventricle output according to the formula VTI $\times \pi \times\left(1 / 2 \mathrm{D}_{\mathrm{LVOT}}\right)^{2}$ (VTI, velocity-time integral; $\mathrm{D}_{\mathrm{LVOT}}$, diameter of LVOT). $\mathrm{D}_{\text {LVOT }}$ was $0.97 \mathrm{~cm}$ and VTI was $5.38 \mathrm{~cm}$. Therefore the stroke volume of left ventricle was almost $4 \mathrm{ml}$, but the right heart stroke volume was $12 \mathrm{ml}$ through Swan-Ganz catcher measurement. The surgeons confirmed that the left atrial suction tube was working well and excluded an increase of left atrial pressure or left ventricular distension. Due to pulmonary artery blood supply and pulmonary venous return mismatching (Table 1), pulmonary congestion was diagnosed as there was no intracardiac shunt at that time. It seemed that there was no cardiac function problems and there were no effective methods to treat this congestion. In addition, the arterial blood gas (ABG) and body temperature was almost in normal ranges. The medical team decided to wean the patient off CPB gradually. Interestingly, the peak airway pressure began to decrease with progressive weaning, and almost recovered to the baseline level finally. The right heart stroke volume was then closer to the stroke volume which was detected by TEE. After the patient was weaned off CPB, D LVOT was $1.57 \mathrm{~cm}$ and VTI was $15.1 \mathrm{~cm}$. Stroke volume of the left ventricle became to be $29.2 \mathrm{ml}$ and the right stroke volume was $30 \mathrm{ml}$ at that moment. The PAP was $45 / 17 \mathrm{mmHg}$ when the patient was completely weaned off $\mathrm{CPB}$. After that, the airway pressure returned to normal and did not increase again during the rest of operation. Subsequently, the patient recovered very well after the surgery.

\section{LITERATURE REVIEW}

The bronchospasm during general anesthesia may encourage anesthesiologists to consider asthma or anaphylaxis (Maslow et al., 2000; Kuo et al., 2010). But asthmatic patients usually have a previous history of asthma and a medical history of bronchial dilator usage. Anaphylaxis is often accompanied by rush, tachycardia, and hypotension as well as bronchospasm. We treated this patient with extensive bronchodilator regimen but it did not show any obvious effect to relieve high airway pressure.

Consequently, we began to consider another type of pulmonary congestion because we found mismatching of the right and left heart stroke volume (Table 1). Through echo measurements and calculation, we can get the left ventricle output according to the formula VTI $\times \pi \times\left(1 / 2 \mathrm{D}_{\mathrm{LVOT}}\right)^{2}$ (Tan et al., 2017; Aligholizadeh et al., 2020). D DVOT was $0.97 \mathrm{~cm}$ and VTI was $5.38 \mathrm{~cm}$. Therefore stroke volume of the left ventricle was about $4 \mathrm{ml}$. But the right heart stroke volume was $12 \mathrm{ml}$ through Swan-Ganz catcher measurement. After the patient was weaned off CPB, DLVOT was $1.57 \mathrm{~cm}$ and VTI was $15.1 \mathrm{~cm}$. The stroke volume of left ventricle became to be about $29.2 \mathrm{ml}$, and the right ventricle stroke volume was $30 \mathrm{ml}$ at that moment. Some researchers reported that there was a special refractory bronchospasm during $\mathrm{CPB}$ without any

TABLE 1 | Hemodynamic and respiratory data.

\begin{tabular}{lccc}
\hline & $\begin{array}{c}\text { After } \\
\text { induction }\end{array}$ & $\begin{array}{c}\text { Before } \\
\text { weaning-off }\end{array}$ & $\begin{array}{c}\text { After } \\
\text { weaning-off }\end{array}$ \\
\hline SV (mL) & 39 & 12 & 30 \\
HR (bpm) & 65 & 90 & 110 \\
LVOT (cm) & 1.8 & 0.97 & 1.57 \\
VTI (cm) & 15.2 & 5.38 & 15.1 \\
LVOT flow (mL) & 38.6 & 4.0 & 29.2 \\
LA suction rate (rpm) & & 6 & 22 \\
P peak (cmH $\left.{ }_{2} \mathrm{O}\right)$ & 20 & 38 & 450 \\
VT (mL) & 450 & 450 & $1: 2$ \\
I:E ratio & $1: 2$ & $1: 2$ & 10 \\
VF (bpm) & 10 & 10 &
\end{tabular}

$H R$, heart rate; I:E ratio, inspiratory to expiratory ratio; $L A$, left atrium; $L V O T$, left ventricular outflow tract; $P_{\text {peak, }}$ peak airway pressure; $S V$, stroke volume; VF, ventilation frequency; VT, tidal volume; VTI, velocity-time integral. 
A

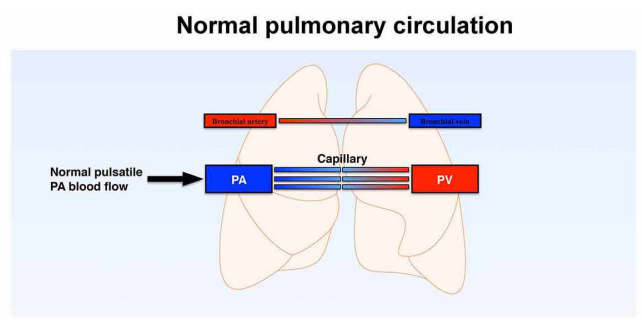

B

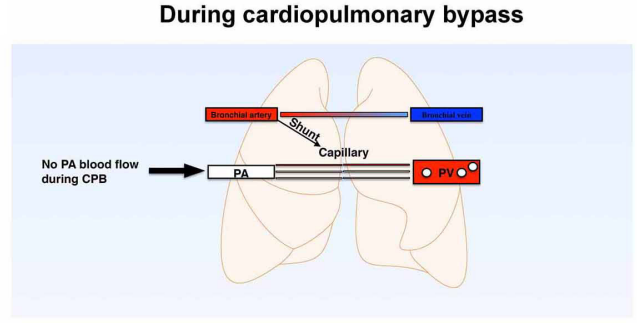

C

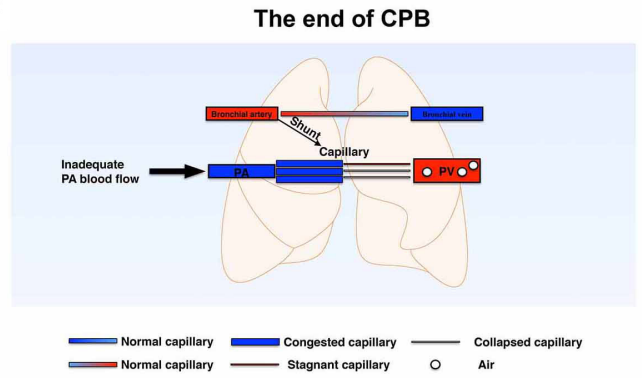

D

Strategies to treat CPB-induced pulmonary congestion

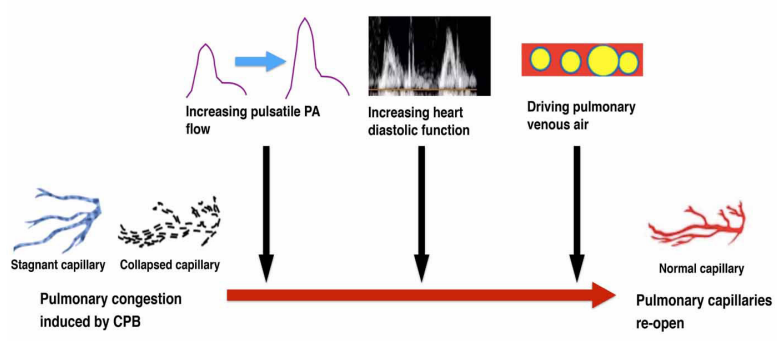

E

Strategies to treat LV failure-induced pulmonary congestion

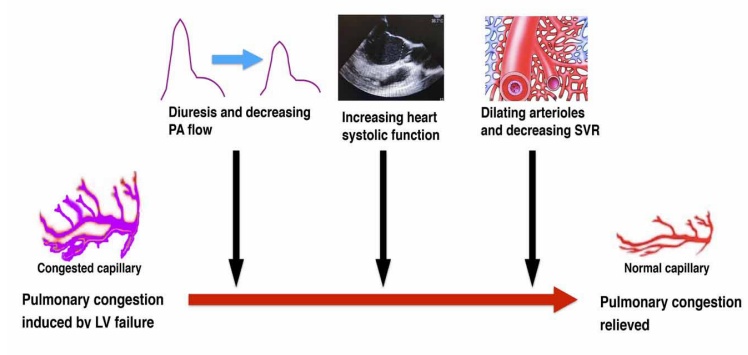

FIGURE 1 | (A) Schematic diagram of pulmonary circulation in the normal physiological state without cardiopulmonary bypass. Both lungs are perfused by the pulmonary artery and bronchial arteries. The blood will be oxygenated in the pulmonary capillaries and returned to the left atrium thought pulmonary vein.

(B) Schematic diagram of pulmonary circulation at the beginning of cardiopulmonary bypass. During cardiopulmonary bypass, the heart stops beating after clamping the aorta. Both lungs are mainly perfused with non-pulsatile bronchial arteries. No blood flows through the pulmonary artery. Some of the pulmonary capillaries will be stagnant or collapsed without normal pulsatile pulmonary blood flow. (C) Schematic diagram of pulmonary circulation at the end of cardiopulmonary bypass. After releasing the aortic clamp, some of the pulmonary vessels will be congested because of the following factors: (1) an increase of pulmonary artery flow; (2) capillary flow stagnant and capillary collapse; (3) post-capillary venous air; (4) left atrial diastolic dysfunction. (D) Schematic diagram of the strategies to treat CPB-induced pulmonary congestion. CPB can promote pulmonary capillary congestion which may be induced mainly by collapsed and stagnant pulmonary capillaries. Increasing PA pulsatile blood flow, increasing heart diastolic function, and driving pulmonary venous air can treat this congestion effectively and therefore re-open the pulmonary circulation. (E) Schematic diagram of the strategies to treat LV failure-induced pulmonary congestion. LV failure can suppress pulmonary venous return and promote pulmonary congestion. Diuresis and decreasing PA flow, increasing heart systolic function, and decreasing SVR can effectively treat this congestion. CPB,

cardiopulmonary bypass; LV, left ventricle; PA, pulmonary artery; PV, pulmonary vein; SVR, systemic vascular resistance.

obvious reasons or any effective bronchial dilators (Hentz et al., 1984; Kawahito et al., 2001). They were not able to explain it further because traditional bronchospasm seldom happened during deep anesthesia like cardiac surgery anesthesia. The pulmonary congestion we reported and discussed may explain some of the reasons. This type of pulmonary congestion presents a decease of pulmonary compliance, good left heart function without high left atrial pressure or high left ventricle end diastolic pressure (LVEDP), moreover, it shows a mismatching between right and left heart stroke volume.

In healthy human heart and lungs, the right heart cardiac output is nearly equal to that of the left heart, except for a tiny anatomic shunt from the right to the left, which will cause a slight difference between right heart and left heart cardiac output (Ming et al., 2014; Petersson and Glenny, 2014).

In some congenital heart disease patients, such as atrial septal defect (ASD) or ventricular septal defect (VSD) patients, there will be a mismatching between the right and left heart cardiac output (Yen, 2015). However, there will be a balance between the right heart inflow and outflow tract. In this patient, we found a significant mismatching between the right and left cardiac output. Theoretically, when the intrapulmonary anatomic shunt is neglected, the right heart cardiac output is equal to the left heart output plus left atrial suction rate during $\mathrm{CPB}$. But through calculation, we found that the right heart output was much more than the left heart output. And importantly, this mismatching revealed that the right heart output flow was more than the pulmonary venous returning, which caused pulmonary congestion instead of blood flow mismatching itself. The reasons for this may be explained as follows: (1) during normal heart work, the pulmonary blood is supplied mainly by the pulmonary artery and bronchial artery, and blood will return to the left atrium through the pulmonary vein (Figure 1A). (2) The pressure gradient of the pulsatile pulmonary artery and the related lower 


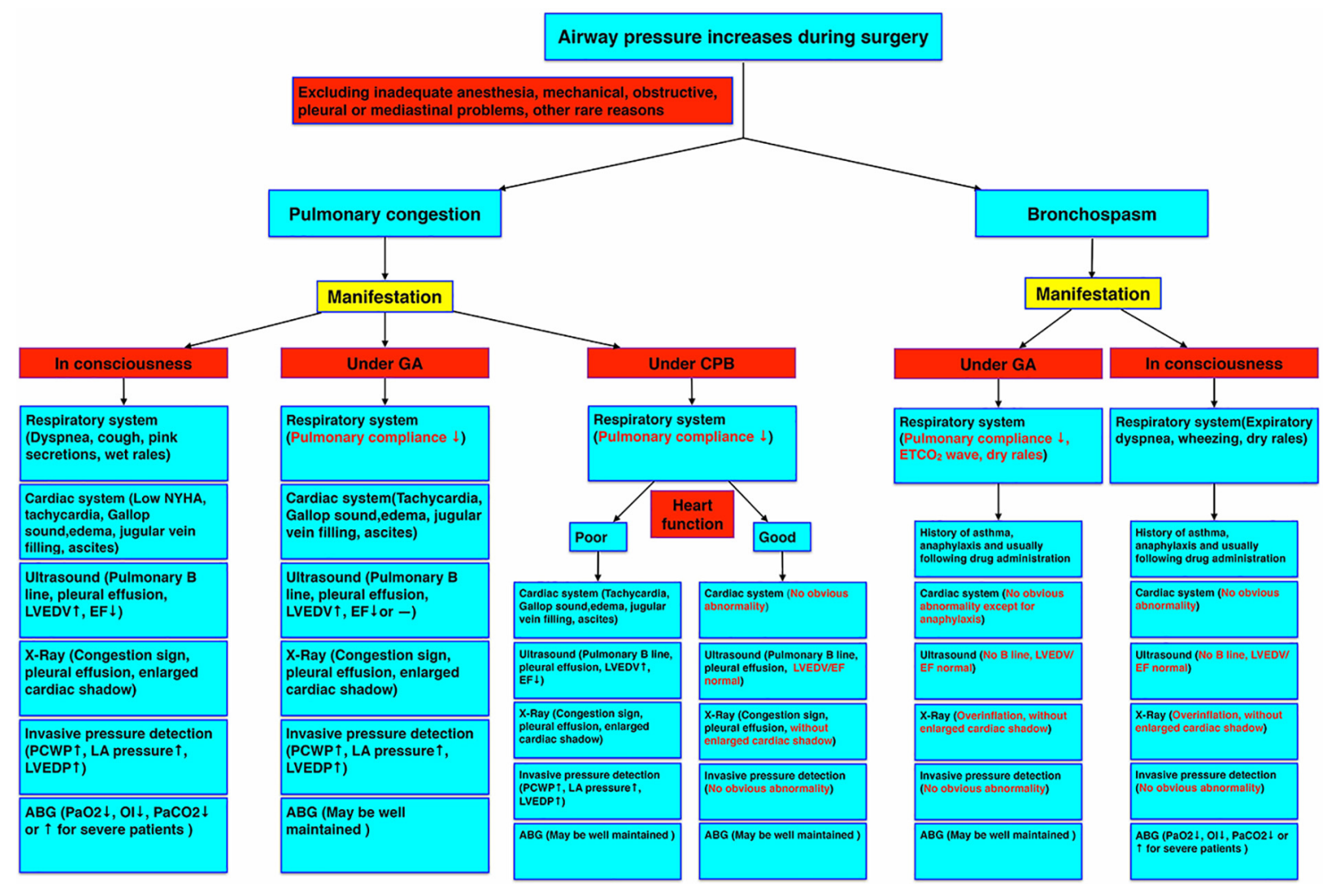

FIGURE 2 | Pulmonary congestion diagnostic criteria under different circumstances. The manifestations of pulmonary congestion under consciousness, general anesthesia, and CPB, and bronchospasm under general anesthesia and consciousness were compared by symptoms and examinations. ABG, arterial blood gas; CPB, cardiopulmonary bypass; EF, ejection fraction; GA, general anesthesia; LA, left atrium; LVEDP, left ventricular end-diastolic pressure; LVEDV, left ventricular end-diastolic volume; NYHA, New York heart association; OI, oxygenation index; PCWP, pulmonary capillary wedge pressure.

pulmonary vein is the main driving force of pulmonary blood flow. However, there are some subtle and reversible changes at the beginning of $\mathrm{CPB}$, and prior to separation from $\mathrm{CPB}$ (Figures 1B, and $\mathbf{C}$ ). It is explained in detail in the following paragraph.

The following changes may have a potential and temporary effect on the pulmonary compliance and airway resistance: (1) the heart stops beating and the pulsatile PAP is missing during $\mathrm{CPB}$, hence the main pulmonary blood driving force will be generated form non-pulsatile bronchial arteries; (2) there will be air filling the pulmonary vein or venules after the left heart opens and then this air will hold part of the pulmonary blood drainage to the left atrium or the CPB machine (Tingleff et al., 1995); (3) pulmonary capillary vessel resistance will be increased with collapses of lung tissue, hypothermia, and nearly stagnant blood flow (Barrios et al., 1959; Kuhn and Turner, 1959; Dekker et al., 2018). In addition, CPB itself may injure the pulmonary endothelium, which has a relatively long-lasting effect of increasing pulmonary arteriolar contractility and promoting pulmonary hypertension (Friedman et al., 1994; Mommerot et al., 2014; Koning et al., 2016). (4) Another important possible mechanism affecting pulmonary vessel resistance is the closed or nearly closed pulmonary microcirculation. Some of the pulmonary capillary vessels will be collapsed and some completely closed during CPB because of hypothermia, nonpulsatile blood flow, thromboxane A2 release, endothelin-1 secretion, complement and neutrophil activation, nuclear factorkappa B pathway, etc. (Huang et al., 1993; Komai et al., 1993; Ross and DiMarco, 2010; Yang et al., 2015; Karmouty-Quintana et al., 2018). Some of these impacts will last for a couple of days after the surgery but some may recover shortly after CPB [e.g., pulmonary vascular resistance will be increased by hypothermia and/or non-pulsatile blood flow and will quickly recover by rewarming and/or resuming pulsatile blood flow (Halsøy et al., 2016; Taylor et al., 1979]. However, when pulmonary artery flow starts to recover after releasing the aortic clamp, it will be much more difficult for the pulmonary artery blood flow to pass through the pulmonary microcirculation unless these closed or nearly closed microcirculations open again. Micro vessel reopening and microvascular dilation needs higher pressure and better pulsatile flow besides rewarming. Pulsatile blood flow may have more shear force and will generate more endothelial relaxing mediators to open microcirculation (Nakano et al., 2001; Thacher et al., 2010). As a result, adequately preloaded right heart work is very important not only to re-open these pulmonary microcirculations but also to drive the residual air out of the pulmonary vessels. (5) The last possible reason affecting 
pulmonary venous drainage is inadequate left atrial diastolic work (Klein et al., 1992; Rossvoll and Hatle, 1993), especially when the left heart cannot fully work very well before complete separation from CPB.

We should differentiate this type of pulmonary congestion from bronchospasm, heart failure, allergic reactions, airway secretions, pleural or mediastinal problems, post-CPB lung injury, anesthetic machine malfunction, and protamine adverse effects, etc. (Figure 2). It is reversible only if we treat it correctly. Some researchers have diagnosed it as refractory bronchospasm without any known cause. However, it is not easy to get the direct evidence of bronchospasm by auscultation and difficult to get the typical bronchospasm $\mathrm{ETCO}_{2}$ waveform, especially during $\mathrm{CPB}$. Also, this type of bronchospasm is unresponsive to regular bronchodilators, corticosteroids, or inotropic drugs. Left atrial pressure measurement or TEE examination may exclude left heart volume overload or contractile dysfunction. Pulmonary ultrasound and echocardiography are very useful, non-invasive, and effective to diagnose pulmonary congestion and cardiac dysfunction in these patients (Picano and Pellikka, 2016; Miglioranza et al., 2017; Platz et al., 2017, 2019). For example, increased numbers of pulmonary ultrasound B lines are typical signs of pulmonary congestion and some patients may have pleural effusion (Gargani et al., 2015; Facchini et al., 2016). Echocardiography may show increased left ventricular enddiastolic volume (LVEDV), a reduced EF, or preserved EF heart failure (Redfield, 2016; Van Aelst et al., 2018). Another important examination for pulmonary congestion is chest X-ray (Liebman et al., 1978; Costanzo and Fein, 1988), yet chest radiography cannot be obtained in time easily during surgery in most operating rooms. ABG measurement will indicate a decreased oxygenation index (OI) or other abnormalities in conscious patients, whereas it may be well maintained in ventilated patients during anesthesia.

The pulmonary circulation during hypothermic $\mathrm{CPB}$ may not be the same as normal circulation during conscious state, so that it is worth while to pay attention to it and calculate specific parameters (Hashimoto et al., 2000; Ege et al., 2003; Buggeskov,

\section{REFERENCES}

Aligholizadeh, E., Teeter, W., Patel, R., Hu, P., Fatima, S., Yang, S., et al. (2020). A novel method of calculating stroke volume using point-of-care echocardiography. Cardiovasc. Ultrasound 18:37.

Barrios, A., Fell, C., and Hamilton, W. F. (1959). Effects of lung collapse on pulmonary blood volume, flow and resistance. Am. J. Physiol. 197, 187-189.

Buggeskov, K. B. (2018). Pulmonary artery perfusion versus no pulmonary perfusion during cardiopulmonary bypass. Dan. Med. J. 65:B5473.

Cops, J., Haesen, S., De Moor, B., Mullens, W., and Hansen, D. (2019). Current animal models for the study of congestion in heart failure: an overview. Heart Fail. Rev. 24, 387-397. doi: 10.1007/s10741-018-9762-4

Costanzo, W. E., and Fein, S. A. (1988). The role of the chest $\mathrm{x}$-ray in the evaluation of chronic severe heart failure: things are not always as they appear. Clin. Cardiol. 11, 486-488.

Dekker, N. A. M., van Meurs, M., van Leeuwen, A. L. I., Hofland, H. M., van Slyke, P., Vonk, A. B. A., et al. (2018). Vasculotide, an angiopoietin-1 mimetic, reduces pulmonary vascular leakage and preserves microcirculatory perfusion during cardiopulmonary bypass in rats. Br. J. Anaesth. 121, $1041-1051$.
2018). According to the above literature and our experience, resuming of normal heart filling and normal right and left heart work are important to re-open the pulmonary microcirculation, restore pulmonary blood flow, drive pulmonary venous air, and reduce pulmonary congestion (Figure 1D). In addition, we also need to avoid high volume ventilation, hypoxemia, hypercapnia, acidosis, inadequate anesthesia depth, and excessive use of pulmonary vascular constrictors. Because the related factors, which will increase pulmonary vascular resistance, may decrease pulmonary venous returning further (Mahmood and Pinsky, 2018; Pinsky, 2018). But for heart failure-induced pulmonary congestion, the treatment strategy is different (Figueroa and Peters, 2006; Pourtaji et al., 2019; Rivas-Lasarte et al., 2019). Left heart failure, no matter acute or chronic, can suppress pulmonary venous returning and promote pulmonary congestion (Gazewood and Turner, 2017; Rubio-Gracia et al., 2018; Skrzypek et al., 2018; Cops et al., 2019). Diuresis, decreasing pulmonary artery flow, increasing left heart systolic function, and decreasing systemic vascular resistance (SVR) can effectively treat heart failure-induced pulmonary congestion effectively (Figure 1E).

Pulmonary congestion due to right/left heart output mismatching will not happen in every $\mathrm{CPB}$ patient and pulmonary tissues are not easily obtained to do histological examination. As a result, there is a barrier to get direct evidence to confirm our hypothesis. However, we have to be cautious about this pathophysiological change to avoid excessive prolonging $\mathrm{CPB}$ time when we encounter similar patients. Further studies are needed to confirm our postulate and clarify the specific pathophysiological mechanism in greater detail.

\section{AUTHOR CONTRIBUTIONS}

JY and YL wrote the manuscript. JS did this anesthesia case, made a thorough analysis of the pathophysiological changes, and finalized the manuscript. All authors contributed to the article and approved the submitted version.

Ege, T., Canbaz, S., Cikirikcioglu, M., Arar, C., Edis, M., and Duran, E. (2003). The importance of pulmonary artery circulation during cardiopulmonary bypass. J. Int. Med. Res. 31, 17-25. doi: 10.1177/147323000303100103

Facchini, C., Malfatto, G., Giglio, A., Facchini, M., Parati, G., and Branzi, G. (2016). Lung ultrasound and transthoracic impedance for noninvasive evaluation of pulmonary congestion in heart failure. J. Cardiovasc. Med. (Hagerstown) 17, 510-517. doi: $10.2459 / \mathrm{jcm} .0000000000000226$

Figueroa, M. S., and Peters, J. I. (2006). Congestive heart failure: diagnosis, pathophysiology, therapy, and implications for respiratory care. Respir. Care 51, 403-412.

Friedman, M., Johnson, R. G., Wang, S. Y., Dai, H. B., Thurer, R. L., Weintraub, R. M., et al. (1994). Pulmonary microvascular responses to protamine and histamine. Effects of cardiopulmonary bypass. J. Thorac. Cardiovasc. Surg. 108, 1092-1099.

Gargani, L., Pang, P. S., Frassi, F., Miglioranza, M. H., Dini, F. L., Landi, P., et al. (2015). Persistent pulmonary congestion before discharge predicts rehospitalization in heart failure: a lung ultrasound study. Cardiovasc. Ultrasound 13:40.

Gazewood, J. D., and Turner, P. L. (2017). Heart failure with preserved ejection fraction: diagnosis and management. Am. Fam. Phys. 96, 582-588. 
Halsøy, K., Kondratiev, T., Tveita, T., and Bjertnaes, L. J. (2016). Effects of constant flow vs. constant pressure perfusion on fluid filtration in severe hypothermic isolated blood-perfused rat lungs. Front. Med. (Lausanne) 3:70.

Hashimoto, K., Sasaki, T., Hachiya, T., Onoguchi, K., Takakura, H., Oshiumi, M., et al. (2000). Influence of cardiopulmonary bypass temperature on circulatory pathophysiology and clinical outcomes. Jpn. Circ. J. 64, 436-444. doi: 10.1253/ jcj.64.436

Hentz, J., Lévy, M., Bauer, M. C., Kieny, M. T., Kretz, J. G., Thiranos, J. C., et al. (1984). Bronchospasm during extracorporeal circulation. Ann. Anesth. Reanim. 3, 219-224.

Huang, H., Ding, W., Su, Z., and Zhang, W. (1993). Mechanism of the preserving effect of aprotinin on platelet function and its use in cardiac surgery. J. Thorac. Cardiovasc. Surg. 106, 11-18. doi: 10.1016/s0022-5223(19)33736-5

Karmouty-Quintana, H., Guignabert, C., Kwapiszewska, G., and Ormiston, M. L. (2018). Editorial: molecular mechanisms in pulmonary hypertension and right ventricle dysfunction. Front. Physiol. 9:1777.

Kawahito, S., Kitahata, H., Tanaka, K., Nozaki, J., and Oshita, S. (2001). Bronchospasm induced by cardiopulmonary bypass. Ann. Thorac. Cardiovasc. Surg. 7, 49-51.

Klein, A. L., Stewart, W. J., Bartlett, J., Cohen, G. I., Kahan, F., Pearce, G., et al. (1992). Effects of mitral regurgitation on pulmonary venous flow and left atrial pressure: an intraoperative transesophageal echocardiographic study. J. Am. Coll. Cardiol. 20, 1345-1352. doi: 10.1016/0735-1097(92)90247-k

Komai, H., Adatia, I. T., Elliott, M. J., de Leval, M. R., and Haworth, S. G. (1993). Increased plasma levels of endothelin-1 after cardiopulmonary bypass in patients with pulmonary hypertension and congenital heart disease. J. Thorac. Cardiovasc. Surg. 106, 473-478. doi: 10.1016/s0022-5223(19)34082-6

Koning, N. J., de Lange, F., Vonk, A. B., Ahmed, Y., van den Brom, C. E., Bogaards, S., et al. (2016). Impaired microcirculatory perfusion in a rat model of cardiopulmonary bypass: the role of hemodilution. Am. J. Physiol. Heart Circ. Physiol. 310, H550-H558.

Kuhn, L. A., and Turner, J. K. (1959). Alterations in pulmonary and peripheral vascular resistance in immersion hypothermia. Circ. Res. 7, 366-374.

Kuo, Y. M., Ting, C. K., Wang, Y. C., Chang, W. K., Wu, H. S., Chan, K. H., et al. (2010). Prophylactic antibiotic administration induced bronchospasm as increased airway pressure during general anesthesia. J. Chin. Med. Assoc. 73, $72-77$.

Liebman, P. R., Philips, E., Weisel, R., Ali, J., and Hechtman, H. B. (1978). Diagnostic value of the portable chest x-ray technic in pulmonary edema. Am. J. Surg. 135, 604-606.

Mahmood, S. S., and Pinsky, M. R. (2018). Heart-lung interactions during mechanical ventilation: the basics. Ann. Transl. Med. 6:349. doi: 10.21037/atm. 2018.04.29

Maslow, A. D., Regan, M. M., Israel, E., Darvish, A., Mehrez, M., Boughton, R., et al. (2000). Inhaled albuterol, but not intravenous lidocaine, protects against intubation-induced bronchoconstriction in asthma. Anesthesiology 93, 1198-1204.

Miglioranza, M. H., Picano, E., Badano, L. P., Sant'Anna, R., Rover, M., Zaffaroni, F., et al. (2017). Pulmonary congestion evaluated by lung ultrasound predicts decompensation in heart failure outpatients. Int. J. Cardiol. 240, 271-278. doi: 10.1016/j.ijcard.2017.02.150

Ming, D. K., Patel, M. S., Hopkinson, N. S., Ward, S., and Polkey, M. I. (2014). The 'anatomic shunt test' in clinical practice; contemporary description of test and in-service evaluation. Thorax 69, 773-775.

Mommerot, A., Denault, A. Y., Dupuis, J., Carrier, M., and Perrault, L. P. (2014). Cardiopulmonary bypass is associated with altered vascular reactivity of isolated pulmonary artery in a porcine model: therapeutic potential of inhaled tezosentan. J. Cardiothorac. Vasc. Anesth. 28, 698-708.

Nakano, T., Tominaga, R., Morita, S., Masuda, M., Nagano, I., Imasaka, K., et al. (2001). Impacts of pulsatile systemic circulation on endothelium-derived nitric oxide release in anesthetized dogs. Ann. Thorac. Surg. 72, 156-162. doi: 10. 1016/s0003-4975(01)02644-3

Petersson, J., and Glenny, R. W. (2014). Gas exchange and ventilation-perfusion relationships in the lung. Eur. Respir. J. 44, 1023-1041.

Picano, E., and Pellikka, P. A. (2016). Ultrasound of extravascular lung water: a new standard for pulmonary congestion. Eur. Heart J. 37, 2097-2104. doi: 10.1093/eurheartj/ehw164
Pinsky, M. R. (2018). Cardiopulmonary interactions: physiologic basis and clinical applications. Ann. Am. Thorac. Soc. 15(Suppl. 1), S45-S48.

Platz, E., Campbell, R. T., Claggett, B., Lewis, E. F., Groarke, J. D., Docherty, K. F., et al. (2019). Lung ultrasound in acute heart failure: prevalence of pulmonary congestion and short- and long-term outcomes. JACC Heart Fail. 7, 849-858.

Platz, E., Merz, A. A., Jhund, P. S., Vazir, A., Campbell, R., and McMurray, J. J. (2017). Dynamic changes and prognostic value of pulmonary congestion by lung ultrasound in acute and chronic heart failure: a systematic review. Eur. J. Heart Fail. 19, 1154-1163.

Pourtaji, A., Jahani, V., Moallem, S. M. H., Karimani, A., and Mohammadpour, A. H. (2019). Application of G-CSF in congestive heart failure treatment. Curr. Cardiol. Rev. 15, 83-90. doi: 10.2174/1573403x14666181031115118

Redfield, M. M. (2016). Heart failure with preserved ejection fraction. N. Engl. J. Med. 375, 1868-1877.

Rivas-Lasarte, M., Álvarez-García, J., Fernández-Martínez, J., Maestro, A., LópezLópez, L., Solé-González, E., et al. (2019). Lung ultrasound-guided treatment in ambulatory patients with heart failure: a randomized controlled clinical trial (LUS-HF study). Eur. J. Heart. Fail. 21, 1605-1613. doi: 10.1002/ejhf. 1604

Ross, F., and DiMarco, Jr. (2010). Postoperative care of the cardiac surgical patient. Surg. Intens. Care Med. 2010, 535-566. doi: 10.1007/978-0-387-77893-8_47

Rossvoll, O., and Hatle, L. K. (1993). Pulmonary venous flow velocities recorded by transthoracic Doppler ultrasound: relation to left ventricular diastolic pressures. J. Am. Coll. Cardiol. 21, 1687-1696. doi: 10.1016/0735-1097(93)90388-h

Rubio-Gracia, J., Demissei, B. G., Ter Maaten, J. M., Cleland, J. G., O’Connor, C. M., Metra, M., et al. (2018). Prevalence, predictors and clinical outcome of residual congestion in acute decompensated heart failure. Int. J. Cardiol. 258, 185-191. doi: 10.1016/j.ijcard.2018.01.067

Skrzypek, A., Mostowik, M., Szeliga, M., Wilczyńska-Golonka, M., DębickaDąbrowska, D., and Nessler, J. (2018). Chronic heart failure in the elderly: still a current medical problem. Folia Med. Cracov. 58, 47-56.

Tan, C., Rubenson, D., Srivastava, A., Mohan, R., Smith, M. R., Billick, K., et al. (2017). Left ventricular outflow tract velocity time integral outperforms ejection fraction and Doppler-derived cardiac output for predicting outcomes in a select advanced heart failure cohort. Cardiovasc. Ultrasound $15: 18$.

Taylor, K. M., Bain, W. H., Russell, M., Brannan, J. J., and Morton, I. J. (1979). Peripheral vascular resistance and angiotensin II levels during pulsatile and nopulsatile cardiopulmonary bypass. Thorax 34, 594-598. doi: 10.1136/thx.34.5. 594

Thacher, T., Gambillara, V., da Silva, R. F., Silacci, P., and Stergiopulos, N. (2010). Reduced cyclic stretch, endothelial dysfunction, and oxidative stress: an ex vivo model. Cardiovasc. Pathol. 19, e91-e98.

Tingleff, J., Joyce, F. S., and Pettersson, G. (1995). Intraoperative echocardiographic study of air embolism during cardiac operations. Ann. Thorac. Surg. 60, 673-677.

Van Aelst, L. N. L., Arrigo, M., Placido, R., Akiyama, E., Girerd, N., Zannad, F., et al. (2018). Acutely decompensated heart failure with preserved and reduced ejection fraction present with comparable hemodynamic congestion. Eur. J. Heart Fail. 20, 738-747. doi: 10.1002/ejhf.1050

Yang, G., Xue, X., Chen, Y., Song, Z., Jiang, Z., and Hu, K. (2015). Effects of cardiopulmonary bypass on lung nuclear factor-kappa B activity, cytokine release, and pulmonary function in dogs. Iran. J. Basic. Med. Sci. 18, 1233-1239.

Yen, P. (2015). ASD and VSD flow dynamics and anesthetic management. Anesth. Prog. 62, 125-130. doi: 10.2344/0003-3006-62.3.125

Conflict of Interest: The authors declare that the research was conducted in the absence of any commercial or financial relationships that could be construed as a potential conflict of interest.

Copyright (c) 2021 Yuan, Li and Sun. This is an open-access article distributed under the terms of the Creative Commons Attribution License (CC BY). The use, distribution or reproduction in other forums is permitted, provided the original author(s) and the copyright owner(s) are credited and that the original publication in this journal is cited, in accordance with accepted academic practice. No use, distribution or reproduction is permitted which does not comply with these terms. 